\section{Review of Sjögren Syndrome: A Comparison of Two Topical Biologic Treatment Options}

\author{
Edward S Jarka ${ }^{1 *}$ and Emily Topi ${ }^{2}$ \\ ${ }^{1}$ The College of Optometry, University of Missouri-St. Louis, St. Louis, USA \\ ${ }^{2}$ Lawrence Eye care, Chicago, USA
}

\begin{abstract}
A brief review of the literature covering the pathogenesis, diagnosis and treatments of Sjögren syndrome are addressed. The most commonly prescribed non-biologic treatments (Cyclosporine A, Steroids, Non-steroidal Anti-inflammatory drugs and Tacrolimus) are reviewed followed by two biologic treatments (Autologous serum and Platelet-rich plasma). A small case series of three patients diagnosed with secondary Sjögren syndrome which had received both biologic treatments (Autologous serum followed by Platelet-rich plasma) are presented. Hypotheses for the superior clinical outcomes of platelet-rich plasma over autologous serum which was observed in the patients are proposed.

Keywords: Autologous serum; Biologics; Dry eye; Growth factor; Platelet-rich plasma; Sjögren syndrome
\end{abstract}

\section{Abbreviations}

AS: Autologous Serum

PRP: Platelet-Rich Plasma

E-PRP: Eye-PRP

SS: Sjögren Syndrome

TNF-alpha: Tumor Necrosis Factor-alpha

RA: Rheumatoid Arthritis

SLE: Systemic Lupus Erythematosus

SP1: Salivary Protein 1

CA6: Carbonic Anhydrase 6

PSP: Parotid Secretory Protein

TFBUT: Tear Fluorescent Break Up Time

OSS: Ocular Staining Score

IL-3: Interleukin-3

NSAID's: Non-Steroidal Anti-Inflammatory Drugs

IFN- $\alpha$ : Interferon-alpha

*Corresponding author: Edward S Jarka, The College of Optometry, University of Missouri-St. Louis, St. Louis, USA, Tel: +1 3145165359; Fax: +1 3145166708; E-mail: jarkae@umsl.edu

Citation: Jarka ES, Topi E (2016) Review of Sjögren Syndrome: A Comparison of Two Topical Biologic Treatment Options. J Ophthalmic Clin Res 3: 024.

Received: July 16, 2016; Accepted: September 15, 2016; Published: September 29, 2016
PDGF: Platelet-Derived Growth Factor

TGF- $\beta$ : Transforming Growth Factor-beta

EGF: Epidermal Growth Factor

FGF: Fibroblast Growth Factor

OSDI: Ocular Surface Disease Index

GvHD: Graft versus Host Disease

IGF-1: Insulin-like Growth Factor

PF4: Platelet Factor 4

BCA-1: B Cell-Attracting chemokine-1

ANA: Anti-Nuclear Antibody

PRK: Photorefractive Keratectomy

\section{Introduction}

Sjögren Syndrome (SS) is an autoimmune disease characteristically observed in middle-aged women that results in the progressive destruction of the lacrimal and salivary glands [1]. The resulting xerophthalmia may progress to cause additional ophthalmic manifestations including corneal scarring, infectious and sterile corneal ulceration and perforation [1]. Although SS is estimated to be the second most common rheumatologic disorder and one of the most prevalent autoimmune conditions encountered by eye care practitioners [2], the most common topical treatments employed by practitioners have not evolved with our expanding knowledge of its pathophysiology. A recent online survey found that the most commonly prescribed topical treatments for aqueous deficient dry eye include cyclosporine A $0.05 \%$ (68\%), fluorometholone $0.1 \%(60 \%)$, loteprednol etabonate $0.5 \%$ (51\%). The only biologic topical treatment mentioned in the survey was autologous serum eye drops (49\%) [3]. We found no mention of Platelet-Rich Plasma (PRP). The purpose of this paper is, firstly, to review the current data available on the pathophysiology, diagnosis and topical treatment of SS-related dry eye. Secondly, it is to compare the clinical response of two topical autologous treatment approaches, Autologous Serum (AS) and Eye-Platelet-Rich Plasma (E-PRP); finally we will propose possible hypotheses on why the clinical response between AS and PRP are different. We fully understand that this small case series does not meet the scientific rigor of a clinical trial but as the number of Sjögren patients who have experienced both treatments increases and with the standardization of the PRP preparation protocol, a clearer delineation of the two procedures may be possible.

\section{Methods}

To obtain data and form the intellectual framework for this review and case series, literature from 2000 to 2015 was screened in an EBSCO host database search using the following keywords: Sjögren syndrome, biologic therapies, corticosteroids, cyclosporine A, tacrolimus, NSAIDs and amniotic membranes. In our review, we have compiled the results of case studies, moderately-sized studies, and randomized controlled trials, dry eye treatment reviews, reviews on pathogenesis of Sjögren disease, and summaries of the most widely-investigated treatment regimens featuring biological treatment options for Sjögren-associated aqueous deficient dry eye. The data was then restricted to topical treatment options to fit the specifics of this review. 


\section{Review of the known pathogenesis of Sjögren syndrome}

Although the pathologic hallmarks of SS are mononuclear cell infiltration of the lacrimal and salivary glands with CD4 T lymphocyte predominating [4] the pathogenesis of Sjögren syndrome manifestations have become known to involve multiple components of the immune system [5]. The chief components are the B-cell lymphocytes, T-cell lymphocytes and dysregulated of cytokines $[5,6]$.

The role of B lymphocytes in SS pathogenesis has been reviewed by Manoussakis et al. [7]. Histological observation of the lacrimal gland has shown approximately $10 \% \mathrm{~B}$ cells and immunoglobulin-secreting plasma cells on biopsy [8]. It is believed that B cell lymphocytes become hyperactive resulting in the hypergammaglobulinemia that is seen in $35-40 \%$ of SS patients [9]. The B cells in SS patients demonstrate markers that initiates the activation, proliferation and differentiation of B cells as well as a marker known as CD20 (also known as B1) that is thought to initiate the activation, proliferation and differentiation of $\mathrm{B}$ cells as well as a ectopic expression of markers like B Cell-Attracting chemokine 1 (BCA-1) that acts as a homing receptor that direct the cells to the lacrimal gland [10,11]. In addition there is evidence that supports an altered $\mathrm{B}$ cell differentiation induced by elevated levels of the B Cell Activating Factor cytokine (BAFF) [12]. The involved B-cells also produce antibodies directed towards the acinar epithelium as well as ducts of exocrine glands, attacking the tissue and interfering with proper tear production and salivary function [13].

Lacrimal gland biopsy, which shows a 75\% involvement from CD4 $\mathrm{T}$ cells, supports the theory that $\mathrm{T}$ cells play a significant role in the generation and perpetuation of inflammatory infiltrates in salivary glands in SS $[14,15]$. The autoantigens expressed on the surface of endothelial cells may trigger the $\mathrm{T}$ cell migration into the lacrimal gland tissue and then, with the association with cell adhesion molecules, be directed to the tissue expressing the antigens. Of course neither lymphocyte population functions in a vacuum; an associated increase in autoantibody production from local B cells also occurs during the $\mathrm{T}$ cell migration into the lacrimal gland [16].

It is also known that dysregulated cytokines function in the pathogenesis of SS [17]. Tumor Necrosis Factor alpha (TNF- $\alpha$ ) have been shown to be over-produced in SS patients and suggested to play a role in the apoptosis of the epithelia in the lacrimal gland [18]. It has also been shown that specific cytokines including IL-10, CD24, CD38, and CD5 become elevated in the blood samples of SS patients which enhances the inflammatory response [19] (Figure 1).

\section{Systemic diagnosis of primary and secondary Sjögren syndrome}

The diagnostic clinical work-up of SS patient involve a series of tests, including serological tests for autoantibody biomarkers, minor salivary gland and lacrimal gland biopsies as well as a panel of ophthalmic tests.

Diagnosis of Sjögren syndrome should never be made without a rheumatologic consult. After a rheumatologic consult, Sjögren syndrome can be classified into one of two forms; primary SS and secondary SS. Although the classification of SS is more for research purposes, the American College of Rheumatology Classification Criteria for Sjögren's syndrome is considered [20]. Primary SS is considered when at least four of the criteria found it table 1 are present. In addition, either criterion 5 or criterion 6 must be included. Sjögren syndrome can be diagnosed in patients who have no

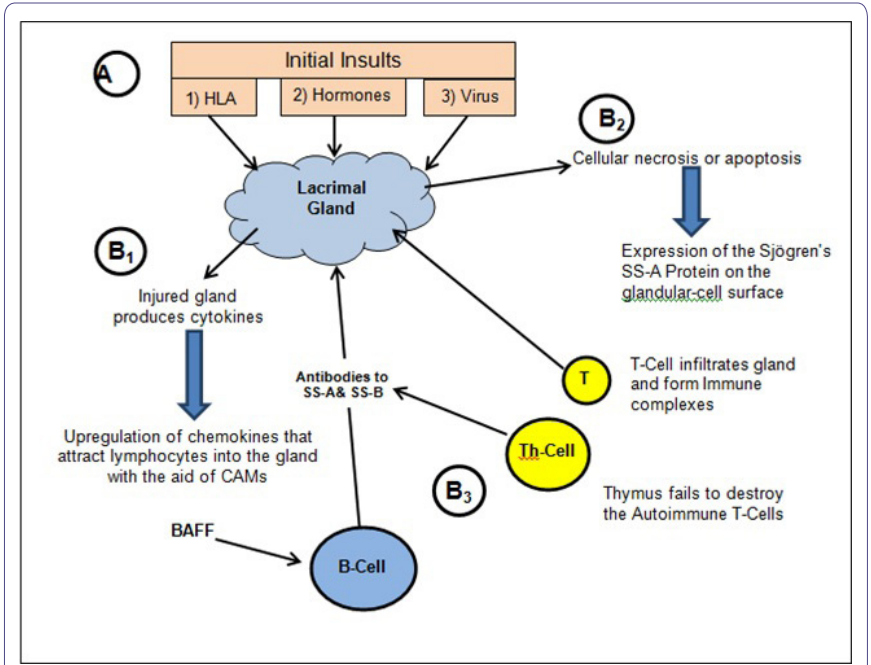

Figure 1: Pathophysiology of Sjögren syndrome.

A brief review of the pathophysiology of Sjögren's syndrome. It is believed that initial insults $(A)$ include: 1 ) the expression of Human Leukocyte Antigen DR (HLA-DR), 2) Sex hormones and 3) Viral exposure namely Epstein-Barr and Human T-cell lymphotrophic virus. The series of responses that take place after the initial insult include; $B_{1}$ : the release of cytokines from the lacrimal gland leading to the upregulation of chemokines that attract lymphocytes; $B_{2}$ : cellular necrosis within the gland leading to autoimmune protein expression on the cell surface of the gland and over-expression of BAFF; $B_{3}$ : B-cell and T-cell contributions to lacrimal gland damage.

sicca symptoms if three of the four objective criteria are present [21]. When the criteria in table 1 are applied a sensitivity of $97.2 \%$ and a specificity of $48.6 \%$ is achieved for the diagnosis of primary [22]. Secondary SS involves primary complications with concurrent autoimmune diseases [1,3]. Rheumatoid Arthritis (RA) is the most common associated comorbidity; others include Hashimoto's thyroiditis, Graft versus Host Disease (GvHD), Sarcoidosis, Systemic Lupus Erythematosus (SLE), Raynaud's disease and Biliary cirrhosis. Thirty percent of patients with RA, SLE or other sclerotic diseases have associated SS [3]. Early diagnosis and monitoring is significant for patients with SS as well as additional investigation to rule out coexisting autoimmune conditions.

Although the objective diagnostic tests discussed above are useful for the eye care practitioner in determining the presence of an aqueous deficient dry eye, it is the laboratory testing that helps narrow the suspicion to a probable Sjögren syndrome. Although the detection of SS-A/Ro, SS-B/La, ANA, and RF are considered important in the diagnosis of SS, they are not always positive in patients with SS, especially in early cases [18]. Recently a novel set of SS autoantibodies which includes; Anti-Salivary Gland Protein 1 (SP1), Anti-Carbonic Anhydrase 6 (CA6) and Anti-Parotid Secretory Protein (PSP), have been shown to be expressed earlier than the traditional SS biomarkers. The early onset inflammatory markers are available in an approved diagnostic panel known as the $\mathrm{Sjö}^{\text {tix }}$ test [23-25]. This finger-prick blood test kit contains all of the items required to perform a finger-prick production of blood which is then placed on a filter paper in a series of spots. The spots are allowed to dry and the sample sent to a lab for the presence of the seven markers.

\section{Ophthalmic diagnostic tests for Sjögren syndrome}

Some standard ophthalmologic tests are used in evaluating for aqueous deficiency in patients with and without SS; therefore, it is important to understand the lack of specificity of these generic dry eye assessments. Some of the most common objective tests for 


\begin{tabular}{|l|l|l|}
\hline No. & Criterion & Criterion Description \\
\hline 1 & Ocular symptoms & $\begin{array}{l}\text { Dry eyes for more than 3 months, foreign-body sen- } \\
\text { sation, use of tear substitutes more than 3 times daily }\end{array}$ \\
\hline 2 & Oral symptoms & $\begin{array}{l}\text { Feeling of dry mouth, recurrently swollen salivary } \\
\text { glands, frequent use of liquids to aid swallowing }\end{array}$ \\
\hline 3 & Ocular signs & $\begin{array}{l}\text { Schirmer test performed without anesthesia }(<5 \mathrm{~mm} \\
\text { in 5 min), positive vital dye staining results }\end{array}$ \\
\hline 4 & Oral signs & $\begin{array}{l}\text { Abnormal salivary scintigraphy findings, abnormal } \\
\text { parotid sialography findings, abnormal sialometry } \\
\text { findings (unstimulated salivary flow }<1.5 \mathrm{~mL} \text { in } 15 \\
\text { min) }\end{array}$ \\
\hline 5 & \multicolumn{2}{|c|}{ Positive minor salivary gland biopsy findings } \\
\hline 6 & \multicolumn{2}{|c|}{ Positive anti-SSA or anti-SSB antibody results } \\
\hline \multicolumn{3}{|c|}{ Table 1: Primary Sjögren syndrome criteria [18]. } \\
\hline
\end{tabular}

aqueous dry eye conditions include schirmer's test, diagnostic dyes, tear osmolarity, one of the few ophthalmic diagnostic tests that measure lacrimal function is the schirmer test which has demonstrated a sensitivity of only $42 \%$ and a specificity of $76 \%$ for Sjögren syndrome [26]. A modification of the schirmer test adds the use of proparacaine $0.5 \%$ to decrease the sensation of the filter paper in the conjunctival sac. This modification provides an improved sensitivity of the test [27].

Diagnostic tests that employ the use of fluorescein, lissamine green and rose bengal dyes and are used in evaluating for aqueous deficiency in patients with and without SS. The most common tests include the use of fluorescein dye for the purpose of assessing the tear stability (TFBUT) and the staining of the ocular tissue. In general, the TFBUT is a measure of an evaporative dry eye rather than aqueous deficient dry eye and a measurement of less than 10 seconds is considered abnormal but not sensitive to patients with SS. Lissamine green is less commonly used in general practice but can provide further information towards SS diagnosis with any of the staining score analysis methods [28]. Rose bengal is another dye that stains the ocular tissue in a similar manner to lissamine green although it is known to cause slightly more discomfort on insertion than lissamine green [29]. The authors have observed lissamine green staining like that shown in figure 2 months before the serologic confirmation of SS or other autoimmune conditions.

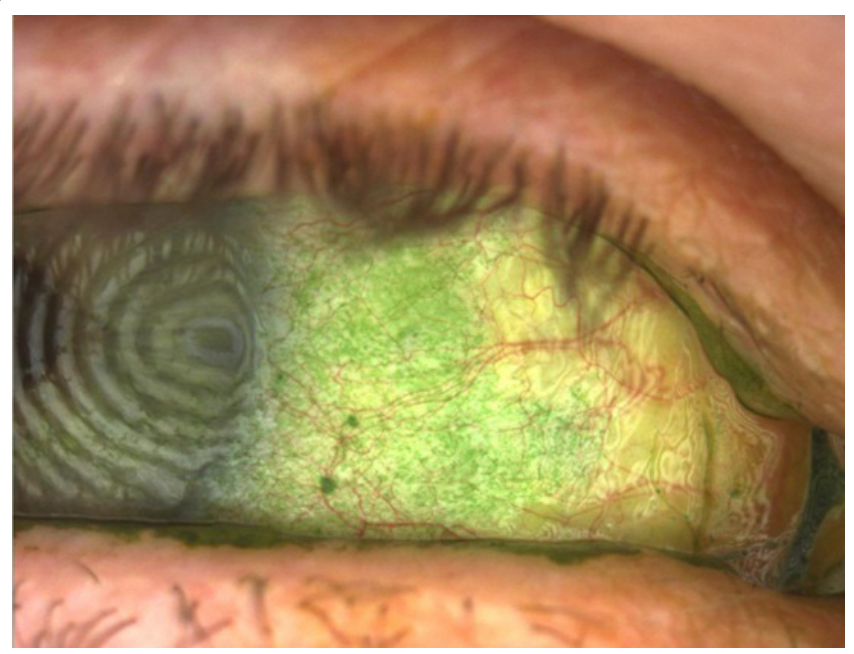

Figure 2: Representative ocular surface appearance of patients seen in this case series. Note the significant lissamine green punctate staining of the bulbar conjunctiva.
Another objective measure of the ophthalmic complications associated with SS includes the use of tear testing. Tear osmolarity has a slightly higher specificity than other objective tests for dry eye, but not specific for SS [30]. Tear analysis of an inflammatory marker, Matrix Metalloproteinase-9 (MMP-9), has been shown to be highly associated with dry eye [31] but the evidence for specificity diagnosing SS is lacking. Testing for the tear protein lactoferrin, which is exclusively produced from the lacrimal gland and more specific to diagnosing conditions that reduced lacrimal gland function like SS [32-34].

A more recently proposed method of stain analysis known as the Ocular Staining Score (OSS) implements a 0 to 12 scale of lissamine green staining combined with salivary gland testing and examination for autoantibodies of SS. Patients with SS tend to have higher scores than patients with keratoconjunctivitis sicca only $[35,36]$. A number of other tests that measure different components of the ocular surface known to be affected in Sjögren's patients that don't require gland biopsies are also in development [29,37].

\section{Review: Common non-biologic topical treatments for Sjögren syndrome}

Cyclosporin A: The most commonly prescribed topical treatment for aqueous dry eye is topical cyclosporine [3]. Topical cyclosporin A is an anti-inflammatory derived from a fungus and has been shown to have many effects on the immune system. Cyclosporine A functions as a secretagogue for the lacrimal gland and also inhibits T-cell activation, thereby limiting lymphocyte-induced apoptosis of acinar cells. The resulting benefits to the dry eye patient have been reported to include increased tear production as well as the inhibition of apoptosis of cells of the ocular surface including an increase in goblet cells $[38,39]$. In patients with severe dry eye and SS a more frequent dosing of topical cyclosporine $0.05 \%$ than twice daily has been suggested [40]. Cyclosporine $0.05 \%$ was shown to improve schirmer test results, reduce corneal staining, and improve subjective symptoms in patients with moderate to severe dry eyes but not necessarily confirmed SS [41]. Topical 2\% cyclosporin A solution has been reported to successfully treat corneal ulcers and decrease apoptosis-related markers in patients with rheumatoid arthritis and secondary Sjögren syndrome [42].

Topical steroids and NSAID's: The next most commonly prescribed topical treatments for aqueous deficient dry eye are topical fluorometholone $0.1 \%$ and loteprednol etabonate $0.5 \%$. These milder steroids such as can reduce the risks associated with topical steroids and thereby allow for a longer treatment periods for primary or secondary SS $[43,44]$. Use of loteprednol etabonate $0.5 \%$ dosed four times daily has been shown to provide significant improvement of symptoms and signs in two weeks compared to a placebo [45]. Loteprednol dosed twice daily has also been shown to help patients transition to cyclosporin-A treatment by reducing the sting that usually accompanies the use of cyclosporine-A [46]. In addition to steroids topical NSAID's have been shown to be useful in resolving symptoms of ocular discomfort in SS patients [47], but should not be used for long periods of time because of the risk associated with corneal perforation [48].

Tacrolimus: Although not used as often as other non-biologic treatments, tacrolimus, a macrolide calcineurin inhibitor, have been shown to inhibit the apoptosis of cells by inhibiting cytokine release of IL-3, 4, 5, 8, Interferon-alpha (IFN- $\alpha$ ) and Tumor Necrosis Factor-alpha (TNF- $\alpha$ ) $[6,49,50]$ and has been shown to have similar immunosuppressive properties to cyclosporine. Originally tacrolimus, like 
cyclosporine, was approved for graft rejection but later has found use in the treatment of ulcerative colitis and as a topical preparation for eczema. A 2012 study demonstrated that tacrolimus could be as effective as cyclosporine-A in dry eye cases of patients with GvHD when cyclosporine-A was proven ineffective for certain patients in the study [51].

\section{Biologic topical treatments for Sjögren syndrome}

According to the FDA website biologic treatment products include a wide range of products such as vaccines, blood and blood components, allergenics, somatic cells, gene therapy, tissues, and recombinant therapeutic proteins [52]. Currently there are no commercially available eye drops that are considered to be biologics, although a few are in development. However, what are available are autologous blood products that contain a number of biologics that have been shown to heal the ocular surface that become damaged either directly or indirectly from the SS pathophysiologic process.

\section{Autologous serum versus platelet-rich plasma}

To understand the differences between Autologous Serum (AS) and Platelet-Rich Plasma (PRP) it is first important to know the differences between serum and plasma. Serum is the clear liquid part of whole blood after the cellular components and the clotting proteins have been removed by centrifugation. Serum includes all proteins not used in blood clotting (coagulation) and all the electrolytes, antibodies, antigens, hormones, and any exogenous substances (e.g., drugs and microorganisms) [53,54]. Fox et al., [55], first used autologous serum eye drops to treat keratoconjunctivitis sicca. Subsequently, AS drops have been used to treat persistent epithelial defects [56], neurotrophic ulcers [57], superior limbic keratoconjunctivitis [58], the ocular surface signs and symptoms associated with graft versus host disease [59], and post-LASIK dry eye [60]. Liu et al., suggested that the topical use of AS provide some growth factors and other nutrients that come from a normally functioning lacrimal gland [61].

On the other hand, plasma is yellow in color and contains clotting proteins like fibrin as well as many of the acellular components found in serum. Marx et al., [62] has shown that plasma also contains concentrated amounts of some important cell-adhesion molecules which promote epithelial migration. It should be noted however that approximately 1,000 proteins have been detected in plasma and it is speculated to contain thousands more [63]. Blood plasma is prepared by the centrifugation of fresh blood containing an anticoagulant. The resulting uppermost yellow layer is then removed from the underlying red layer which contains most of the formed elements of the blood. Platelet-rich plasma, as the name implies, is plasma with concentrated levels of platelets. Within the platelets are the alpha granules that, upon activation, release a number of bioactive proteins promoting tissue repair [64]. The bioactive proteins include Platelet-Derived Growth Factor (PDGF), Transforming Growth Factor-beta (TGF- $\beta$ ), Epidermal Growth Factor (EGF), Fibroblast Growth Factors (FGF) and Insulin-like Growth Factor-1 (IGF-1), as well as cytokines, such as Platelet Factor 4 (PF4) and Cluster of Differentiation 40 Ligand (CD40L) [65-67]. Platelet-Rich Plasma (PRP) has been used to treat acute corneal chemical injury [68], severe dry eye [69], dormant ulcers [70], including neurotrophic, exposure and limbal deficiency with corneal ulcer after herpetic keratitis, and three case reports of corneal ulcer which included neurotrophic ulcer, exposure corneal ulcer, and limbal deficiency with corneal ulcer after herpetic keratitis
[71]. Selected components of tears, serum and PRP are compared in table $2[72,73]$.

\begin{tabular}{|c|c|c|c|}
\hline & Tears & Serum & PRP \\
\hline $\mathbf{p H}$ & 7.4 & 7.4 & 7.96 \\
\hline Osmolarity & 298 & 296 & 347 \\
\hline EGF $(\mathbf{n g} / \mathbf{m l})$ & 0.25 & 0.5 & 1.7 \\
\hline TGF- $\boldsymbol{\beta}(\mathbf{n g} / \mathbf{m l})$ & $2-10$ & $6-33$ & 67 \\
\hline PDGF $(\mathbf{n g} / \mathbf{m l})$ & 0.03 & 1.7 & 12.6 \\
\hline VEGF $(\mathbf{p g} / \mathbf{m l})$ & 6.15 & 91.8 & 204.5 \\
\hline Fibronectin $(\mathbf{\mu g} / \mathbf{m l})$ & 21 & 205 & 301 \\
\hline
\end{tabular}

Table 2: Concentration of selected components of tears, serum and platelet rich plasma $[65,66,70]$.

\section{Abbreviations}

EGF: Epithelial Growth Factor

TGF- $\beta$ : Transforming Growth Factor-beta

PDGF: Platelet Derived Growth Factor

VEGF: Vascular Endothelial Growth Factor

\section{Three case reports of Sjögren syndrome}

Case \# 1: SL is a 38 year old female with a long history of dry eyes. Her eye discomfort was significant enough that she had difficulty working on the computer which was vital for her job. A survey of symptoms was administered with the Ocular Surface Disease Index (OSDI) and her result would suggest that her dry eye is mild. Although she reports "having dry eyes all my life" she had lasik about 5 years prior to her visit. Her medical history was significant for Sjögren syndrome and systemic lupus erythematosus. Prior treatment for her dry eyes included a variety of artificial tears gels and ointments, a sleep mask and 5-6 years of restasis and autologous serum.

Her vision without correction was 20/20 from each eye. Her lid margins were notably reddened from telangiectasia and thickened. Her tears were debris-filled with a TFBUT of 4 seconds in the right eye and 5 second in the left. Phenol red thread test was measured at 10 $\mathrm{mm}$ from the right and $8 \mathrm{~mm}$ from the left eye. Her oxford ocular surface staining score was consistent with that of a moderate to marked level of severity in both eyes.

Her presentation was consistent with dry eye with mixed etiologies including blepharitis, Sjögren syndrome and a history of refractive surgery. A 50\% concentrate of PRP was prepared and dosed twice a day in each eye. The patient showed marked improvement in 3 weeks in both signs and symptoms of her ocular surface staining and lid margin telangiectasia. In the months that followed she remained stable and only worsened when she discontinued the use of the PRP drops. Today she continues to receive PRP drops and on occasion requires lid hygiene and expression.

It is interesting to note the disparity between the ocular signs and symptoms as they relate to the OSDI. When asked about her responses on the OSDI she suggested that she had been living with the condition for so long that her interpretation of severity has changed.

Case \#2: KD is a 72 year old female who was referred for preparation of platelet rich plasma after a poor response to numerous preparations of autologous serum. She had been diagnosed with Sjögren syndrome years earlier and presents with best corrected acuity of 20/50 in each eye. She had surgery for cataracts $4-5$ years ago. She reported using a number of other treatments for her dry eye which also failed.

Her tear assessment showed a schirmer test of $1 \mathrm{~mm}$ in each eye and an immediate break-up of the TFBUT. Staining of the ocular 
surface showed a moderate to marked level of severity on the Oxford ocular surface staining schema.

She was prepared a $50 \%$ concentrate of PRP and instructed to use the drops 2-3 times a day in each eye. Additional treatment included the use of preservative free artificial tears 4 times per day between PRP drops. The patient was instructed to call the office in one month because the season and distance prevented her from returning in one month. The patient reported significant improvement in her comfort and vision compared to her autologous serum drops. Two months later she returned with 20/40+ vision from each eye, a TFBUT of 3 seconds in each eye and notable improvement in her ocular surface staining appearance.

Case \#3: EA originally was a 66 year old woman who originally presented to the office with complaints of ocular pain from both eyes with the left eye slightly worse than the right. She reported being diagnosed with Sjögren syndrome about 16 years ago and has experienced periods of eye pain and blurred vision that waxed and waned. Subsequently she has also been diagnosed with Rheumatoid arthritis and Lupus. Her OSDI responses confirmed a severe dry eye. Her history was significant for Lasik, PRK, cataract surgery and Yag capsulotomy in both eyes. She reports minimal to no improvement from a number of treatments for her dry eye which included; a variety of artificial tears, gels and ointments, bandage lenses, restasis, punctal plugs, lacriserts, fish oil supplements and autologous serum dosed between 6-10 times per day.

She presented with very narrow palpebral fissures because of her discomfort. Visual acuity was measured at 20/100 from her right eye and 20/200 from her left eye. She was found to have an immediate TFBUT in both eyes and staining of the cornea and conjunctival ocular surface consistent with a moderate to marked severity on the Oxford ocular surface staining scale. After insertion of topical anesthetic she was found to also demonstrate corneal filaments in the central cornea of each eye.

A 50\% PRP concentrate was dispensed to be dosed 2-3 times a day in each eye. She discontinued all other treatments except for the fish oil supplements and the use of preservative-free artificial tears 3-4 times between PRP doses. After 6 weeks of treatment her ocular surface began to improve and her vision improved to 20/30 from her right eye and 20/60 from her left eye. Although she has experienced worsening of her systemic symptoms related to the Sjögren's, Rheumatoid arthritis and Lupus, she continues on her current treatment which keeps her eyes comfortable and her vision stable to work as a research consultant.

\section{Discussion and Conclusion}

Sjögren syndrome, whether in the primary or secondary form, can cause disabling pain and profoundly disrupted vision. Although there are many topical preparations available for the ophthalmic complications of SS, only two are considered to be biologic and autologous. All of the patients in this series failed on their previous treatments including autologous serum, but reported improvement in symptoms, vision or both after beginning a 50\% concentrate of PRP dosed between 2-4 times per day.

Alio et al., [69] speculated that the main difference between PRP and AS is the presence of platelets in the former and, due to this fact, a prolonged release of growth factors. Other authors have offered hypotheses to explain the different clinical responses between AS and PRP. A study comparing AS to PRP in patients with persistent corneal epithelial defect after infectious keratitis suggested that the higher levels of epitheliotropic growth factors are responsible for faster healing observed in patients taking PRP compared to patients taking AS [74]. In a study using PRP for the treatment of refractory ocular GvHD the authors noted that some of their subjects that responded favorably to PRP had previously failed with AS [75].

It has been suggested that the similarity between normal tears and serum is the reason for the positive clinical improvement observed with AS in Sjögren syndrome patients, but today it is more precise to say that it is the addition of the growth factors found in AS that is responsible for this improvement. It is natural to conclude from the studies reviewed in this paper as well as our reported clinical observations that the improved clinical response of PRP compared to AS is due to the prolonged increased concentration of growth factors found in PRP. Recent studies suggest nerve Growth Factor (NGF) may play a key role in healing of the conjunctival surface damaged by hyperosmolar stress [76]. Others have suggested that it may be the presence of multiple growth factors rather than a single growth factor that lead to the varying responses [77] including DNA synthesis, cellular proliferation [78], anti-apoptotic signaling and alteration of cell morphology and motility through association with the actin cytoskeleton [74,79]. This observation doesn't take into account the other bioactive proteins within the alpha granules that act as co-factors for the growth factors.

Although AS has been used in the past for the treatment of severe ocular surface disease, we believe that the improved clinical response that has been observed by us and others with PRP should be the preferred treatment in moderate and severe dry eye conditions with multiple contributing factors like Sjögren syndrome. We are working on methods to enhance the beneficial effects of PRP and hopefully show that an earlier exposure to PRP may delay the ocular complications from becoming embedded until more effective systemic treatments become available.

\section{Conflict of Interest}

The authors have no conflict of interest with any company or firm.

\section{References}

1. Mavragani CP, Moutsopoulos HM (2014) Sjögren's Syndrome. Annual Review of Pathology: Mechanisms of Disease 9: 273-285.

2. Helmick CG, Felson DT, Lawrence RC, Gabriel S, Hirsch R, et al. (2008) Estimates of the prevalence of arthritis and other rheumatic conditions in the United States. Part I. Arthritis Rheum 58: 15-25.

3. Sy A, O'Brien KS, Liu MP, Cuddapah PA, Acharya NR, et al. (2015) Expert opinion in the management of aqueous Deficient Dry Eye Disease (DED). BMC Ophthalmology 15: 133.

4. Alunno A, Carubbi F, Bistoni O, Caterbi S, Bartoloni E, et al. (2014) CD4(-) CD8(-) T-cells in primary Sjögren's syndrome: association with the extent of glandular involvement. J Autoimmun 51: 38-43.

5. Derk CT (2005) Sjögren's syndrome: models of pathogenesis and treatment targets. Expert Opinion on Therapeutic Patents 15: 1587-1594.

6. Furuzawa-Carballeda J, Hernandez-Molina G, Lima G, Rivera-Vicencio Y, Ferez-Blando K, et al. (2013) Peripheral regulatory cells immunophenotyping in Primary Sjögren's Syndrome: a cross-sectional study. Arthritis Res Ther 15: 68.

7. Manoussakis MN, Moutsopoulos HM (2006) Sjögren's syndrome. In: Rose NR, Mackay IR (eds.). The autoimmune diseases, (4 ${ }^{\text {th }}$ edn), Elsevier Academic Press, St Louis, Missouri, USA.

8. Parkin B, Chew JB, White VA, Garcia-Briones G, Chhanabhai M, et al. (2005) Lymphocytic infiltration and enlargement of the lacrimal glands: a new subtype of primary Sjögren's syndrome? Ophthalmology 112: 2040-2047. 
9. Kroese FG, Abdulahad WH, Haacke E, Bos NA, Vissink A, et al. (2014) B-cell hyperactivity in primary Sjögren's syndrome. Expert Rev Clin Immunol 10: 483-499.

10. Tedder TF, Boyd AW, Freedman AS, Nadler LM, Schlossman SF (1985) The $B$ cell surface molecule B1 is functionally linked with B cell activation and differentiation. J Immunol 135: 973-979.

11. Amft N, Curnow SJ, Schell-Toellner D, Devadas A, Oates J, et al. (2001) Ectopic expression of the B cell-attracting chemokine BCA-1 (CXCL13) on endothelial cells within lymphoid follicle contributes to the establishment of germinal center-like structures in Sjögren's Syndrome. Arthritis Rheum 44: 2633-2641.

12. Groom J, Kalled SL, Cutler AH, Olson C, Woodcock SA, et al. (2002) Association of BAFF/BLyS overexpression and altered $B$ cell differentiation with Sjögren's syndrome. J Clin Invest 109: 59-68.

13. García-Carrasco M, Ramos-Casals M, Rosas J, Pallarés L, Calvo-Alen J, et al. (2002) Primary Sjögren syndrome: clinical and immunologic disease patterns in a cohort of 400 patients. Medicine (Baltimore) 81: 270-280.

14. Hillen MR, Ververs FA, Kruize AA, Van Roon JA (2014) Dendritic cells T-cells and epithelial cells: a crucial interplay in immunopathology of primary Sjögren's syndrome. Expert Rev Clin Immunol 10: 521-531.

15. Gao J, Morgan G, Tieu D, Schwalb TA, Luo JY, et al. (2004) ICAM-1 expression predisposes ocular tissues to immune-based inflammation in dry eye patients and Sjögrens syndrome-like MRL/lpr mice. Exp Eye Res 78: 823-835.

16. Hansen A, Daridon C, Dörner T (2010) What do we know about memory B cells in primary Sjögren's syndrome? Autoimmun Rev 9: 600-603.

17. Roescher N, Tak PP, Illei GG (2010) Cytokines in Sjogren's syndrome: potential therapeutic targets. Ann Rheum Dis 69: 945-948.

18. Matsumura R, Umemiya K, Goto T, Nakazawa T, Ochiai K, et al. (2000) Interferon gamma and tumor necrosis factor alpha induce Fas expression and anti-Fas mediated apoptosis in a salivary ductal cell line. Clin Exp Rheumato 18: $311-318$

19. Tzioufas AG, Voulgarelis M (2007) Update on Sjögren's syndrome autoimmune epithelitis: from classification to increased neoplasias. Best Pract Res Clin Rheumatol 21: 989-1010.

20. Shiboski SC, Shiboski CH, Criswell LA, Baer AN, Challacombe S, et al. (2012) American College of Rheumatology classification criteria for Sjögren's syndrome: a data-driven, expert consensus approach in the Sjögren's International Collaborative Clinical Alliance cohort. Arthritis Care Res (Hoboken) 64: 475-487.

21. Gálvez J, Sáiz E, López P, Pina MF, Carrillo A, et al. (2009) Diagnostic evaluation and classification criteria in Sjögren's Syndrome. Joint Bone Spine 76: $44-49$

22. Liew MS, Zhang M, Kim E, Akpek EK (2012) Prevalence and predictors of Sjogren's syndrome in a prospective cohort of patients with aqueous-deficient dry eye. Br J Ophthalmol 96: 1498-1503.

23. Suresh L, Malyavantham K, Shen L, Ambrus JL (2015) Investigation of novel autoantibodies in Sjögren's syndrome utilizing Sera from the Sjögren's international collaborative clinical alliance cohort. BMC Ophthalmol 15: 38.

24. Beckman KA (2014) Detection of early markers for Sjögren syndrome in dry eye patients. Cornea 33: 1262-1264.

25. Vishwanath S, Everett S, Shen L, Malyavantham K, Suresh L, et al. (2014) Xerophthalmia of Sjogren's Syndrome Diagnosed with Anti-Salivary Gland Protein 1 Antibodies. Case Rep Ophthalmol 5: 186-189.

26. Versura $P$, Frigato $M$, Cellini M, Mulè R, Malavolta N, et al. (2007) Diagnostic performance of tear function tests in Sjogren's syndrome patients. Eye (Lond) 21: $229-237$

27. Li N, Deng XG, He MF (2012) Comparison of the Schirmer I test with and without topical anesthesia for diagnosing dry eye. Int $\mathrm{J}$ Ophthalmol 5: 478481.
28. Savini G, Prabhawasat P, Kojima T, Grueterich M, Espana E, et al. (2008) The challenge of dry eye diagnosis. Clin Ophthalmol 2: 31-55.

29. Zeev MS, Miller DD, Latkany R (2014) Diagnosis of dry eye disease and emerging technologies. Clin Ophthalmol 8: 581-590.

30. Lemp MA, Bron AJ, Baudouin C, Benítez Del Castillo JM, Geffen D, et al (2011) Tear osmolarity in the diagnosis and management of dry eye disease. Am J Ophthalmol 151: 792-798.

31. Sambursky R, Davitt WF 3rd, Friedberg M, Tauber S (2014) Prospective, multicenter, clinical evaluation of point-of-care matrix metalloproteinase- 9 test for confirming dry eye disease. Cornea 33: 812-818.

32. Ohashi Y, Ishida R, Kojima T, Goto E, Matsumoto Y, et al. (2003) Abnorma protein profiles in tears with dry eye syndrome. Am J Ophthalmol 136: 291 299

33. Versura P, Bavelloni A, Grillini M, Fresina M, Campos EC (2013) Diagnostic performance of a tear protein panel in early dry eye. Mol Vis 19: 1247-1257.

34. Karns K, Herr AE (2011) Human tear protein analysis enabled by an alkaline microfluidic homogeneous immunoassay. Anal Chem 83: 8115-8122.

35. Cornec D, Jamin C, Pers JO (2014) Sjögren's syndrome: where do we stand, and where shall we go? J Autoimmun 51: 109-114.

36. Whitcher JP, Shiboski CH, Shiboski SC, Heidenreich AM, Kitagawa K, et al (2010) A simplified quantitative method for assessing keratoconjunctivitis sicca from the Sjögren's Syndrome International Registry. Am J Ophthalmo 149: 405-415.

37. [No authors listed] (2007) Methodologies to diagnose and monitor dry eye disease: report of the Diagnostic Methodology Subcommittee of the International Dry Eye WorkShop (2007). Ocul Surf 5: 108-152.

38. Rao SN (2010) Topical cyclosporine $0.05 \%$ for the prevention of dry eye disease progression. J Ocul Pharmacol Ther 26: 157-164.

39. Matsuda S, Koyasu S (2000) Mechanisms of action of cyclosporine. Immunopharmacology 47: 119-125.

40. Dastjerdi MH, Hamrah P, Dana R (2009) High-frequency topical cyclosporine $0.05 \%$ in the treatment of severe dry eye refractory to twice-daily regimen. Cornea 28: 1091-1096.

41. Sall K, Stevenson OD, Mundorf TK, Reis BL (2000) Two multicenter, randomized studies of the efficacy and safety of cyclosporine ophthalmic emulsion in moderate to severe dry eye disease. CsA Phase 3 Study Group. Ophthalmology 107: 631-639.

42. Herzlich A (2015) Ophthalmologic Manifestations of Sjogren Syndrome. Medscape, New York, USA.

43. Ramos-Casals M, Tzioufas AG, Stone JH, Sisó A, Bosch X (2010) Treatment of primary Sjögren syndrome: a systematic review. JAMA 304: 452-460.

44. Coursey TG, de Paiva CS (2014) Managing Sjögren's Syndrome and nonSjögren Syndrome dry eye with anti-inflammatory therapy. Clin Ophthalmo 8: $1447-1458$

45. Pflugfelder SC, Maskin SL, Anderson B, Chodosh J, Holland EJ, et al. (2004) A randomized, double-masked, placebo-controlled, multicenter comparison of loteprednol etabonate ophthalmic suspension, $0.5 \%$, and placebo for treatment of keratoconjunctivitis sicca in patients with delayed tear clearance. Am J Ophthalmol 138: 444-457.

46. Sheppard JD, Scoper SV, Samudre S (2011) Topical Loteprednol Pretreatment Reduces Cyclosporine Stinging in Chronic Dry Eye Disease. J of Ocular Pharm and Therap 27: 23-27.

47. Aragona P, Stilo A, Ferreri F, Mobrici M (2005) Effects of the topical treatment with NSAIDs on corneal sensitivity and ocular surface of Sjögren's syndrome patients. Eye (Lond) 19: 535-539.

48. Ramos-Casals M, Brito-Zerón P, Sisó-Almirall A, Bosch X, Tzioufas AG (2012) Topical and systemic medications for the treatment of primary Sjögren's syndrome. Nat Rev Rheumatol 8: 399-411. 
49. Ogutcen-Toller M, Gedik R, Gedik S, Gedik F (2012) Sjögren syndrome: a case report and review of the literature. West Indian Med.

50. Reitamo S, Van Leent EJ, Ho V, Harper J, Ruzicka T, et al. (2002) Efficacy and safety of tacrolimus ointment compared with that of hydrocortisone acetate ointment in children with atopic dermatitis. J Allergy Clin Immunol 109: 539-546.

51. Marco E, Udaondo P, García-Delpech S, Vazquez A, Diaz-Llopis M (2013) Treatment of refractory dry eye associated with graft versus host disease with 0.03\% tacrolimus eyedrops. J Ocul Pharmacol Ther 29: 776-783.

52. http://www.fda.gov/AboutFDA/CentersOffices/OfficeofMedicalProductsandTobacco/CBER/ucm133077.htm

53. Geerling G, Maclennan S, Hartwig D (2004) Autologous serum eye drops for ocular surface disorders. Br J Ophthalmol 88: 1467-1474.

54. López-García JS, García-Lozano I, Rivas L, Martínez-Garchitorena J (2007) [Use of autologous serum in ophthalmic practice]. Arch Soc Esp Oftalmo 82: 9-20.

55. Fox R, Chan R, Michelson JB, Belmont JB, Michelson PE (1984) Beneficial effect of artificial tears made with autologous serum in patients with keratoconjunctivitis sicca. Arthritis Rheum 27: 459-461.

56. Tsubota K, Goto E, Shimmura S, Shimazaki J (1999) Treatment of persistent corneal epithelial defect by autologous serum application. Ophthalmology 106: 1984-1989.

57. Matsumoto Y, Dogru M, Goto E, Ohashi Y, Kojima T, et al. (2004) Autologous serum application in the treatment of neurotrophic keratopathy. Ophthalmology 111: 1115-1120.

58. Goto E, Shimmura S, Shimazaki J, Tsubota K (2001) Treatment of superior limbic keratoconjunctivitis by application of autologous serum. Cornea 20: 807-810.

59. Ogawa Y, Okamoto S, Mori T, Yamada M, Mashima Y, et al. (2003) Autologous serum eye drops for the treatment of severe dry eye in patients with chronic graft-versus-host disease. Bone Marrow Transplant 31: 579-583.

60. Noda-Tsuruya T, Asano-Kato N, Toda I, Tsubota K (2006) Autologous serum eye drops for dry eye after LASIK. J Refract Surg 22: 61-66.

61. Liu L, Hartwig D, Harloff S, Herminghaus P, Wedel T, et al. (2006) Cornea epitheliotrophic capacity of three different blood-derived preparations. Invest Ophthalmol Vis Sci 47: 2438-2444.

62. Marx RE (2004) Platelet-rich plasma: evidence to support its use. J Oral Maxillofac Surg 62: 489-496.

63. http://www.sigmaaldrich.com/life-science/metabolomics/enzyme-explorer/ learning-center/plasma-blood-protein/blood-basics.html

64. Anitua E, Andia I, Ardanza B, Nurden P, Nurden AT (2004) Autologous platelets as a source of proteins for healing and tissue regeneration. Thromb Haemost 91: 4-15.
65. Stassen JM, Arnout J, Deckmyn H (2004) The hemostatic system. Curr Med Chem 11: 2245-2260.

66. Klinger MH, Jelkmann W (2002) Role of blood platelets in infection and inflammation. J Interferon Cytokine Res 22: 913-922.

67. Boehlen F, Clemetson KJ (2001) Platelet chemokines and their receptors: what is their relevance to platelet storage and transfusion practice? Transfus Med 11: 403-417.

68. Panda A, Jain M, Vanathi M, Velpandian T, Khokhar S, et al. (2012) Topical autologous platelet-rich plasma eyedrops for acute corneal chemical injury. Cornea 31: 989-993.

69. Alio JL, Colecha JR, Pastor S, Rodriguez A, Artola A (2007) Symptomatic dry eye treatment with autologous platelet-rich plasma. Ophthalmic Res 39: 124-129.

70. Alio JL, Abad M, Artola A, Rodriguez-Prats JL, Pastor S, et al. (2007) Use of autologous platelet-rich plasma in the treatment of dormant corneal ulcers. Ophthalmology 114: 1286-1293.

71. Wu TE, Chen CJ, Chao-Chien Hu, Cheng-Kuo Cheng (2015) Easy-to-prepare autologous platelet-rich plasma in the treatment of refractory corneal ulcers. Taiwan Journal of Ophthalmology 5: 132-135.

72. Vesaluoma M, Teppo AM, Grönhagen-Riska C, Tervo T (1997) Platelet-derived growth factor-BB (PDGF-BB) in tear fluid: a potential modulator of corneal wound healing following photorefractive keratectomy. Curr Eye Res 16: 825-831.

73. Rentka A, Hársfalvi J, Berta A, Köröskényi K, Szekanecz Z, et al. (2015) Vascular Endothelial Growth Factor in Tear Samples of Patients with Systemic Sclerosis. Mediators of Inflamm 2015: 573681.

74. Kyoung MK, Yong-Tae S, Hong KK (2012) Effect of autologous platelet-rich plasma on persistent corneal epithelial defect after infectious keratitis. Jpn J Ophthalmol 56: 544-550.

75. Pezzotta S, Del Fante C, Scudeller L, Cervio M, Antoniazzi ER, et al. (2012) Autologous platelet lysate for treatment of refractory ocular GVHD. Bone Marrow Transplant 47: 1558-1563.

76. Kang SS, Ha SJ, Kim ES, Shin JA, Kim JY, et al. (2014) Effect of nerve growth factor on the in vitro induction of apoptosis of human conjunctival epithelial cells by hyperosmolar stress. Invest Ophthalmol Vis Sci 55: 535-541.

77. Klenkler B, Sheardown H (2004) Growth factors in the anterior segment: role in tissue maintenance, wound healing and ocular pathology. Exp Eye Res 79: 677-688.

78. Czarkowska-Paczek B, Bartlomiejczyk I, Przybylski J (2006) The serum levels of growth factors: PDGF, TGF-beta and VEGF are increased after strenuous physical exercise. J Physiol Pharmacol 57: 189-197.

79. López-Plandolit S, Morales MC, Freire V, Etxebarría J, Durán JA (2010) Plasma rich in growth factors as a therapeutic agent for persistent corneal epithelial defects. Cornea 29: 843-848. 